\title{
Giant inguinoscrotal hernia: An emergency presentation with life-threatening sepsis
}

\author{
TP Burke, KM Joyce, K Ahmed, PS Waters, \\ W Khan, K Barry
}

\section{CASE REPORT}

A 74-year-old male was brought by ambulance to the emergency department with a 12-hour history of an acutely painful scrotum with associated rapidly progressing discoloration of the overlying scrotal skin. This was on a background of a giant inguinoscrotal hernia present for approximately 12 years for which he had previously declined operative intervention. Other than well controlled hypertension, his past medical was unremarkable. Upon arrival in the emergency department, he was noted as being markedly hypotensive and displaying clinical signs consistent with septic shock. His scrotum was noted as being grossly enlarged with a black discoloration (Figure 1). Several fluids filled bullae were noted on the scrotal skin (Figure 2). On physical examination his abdomen was soft and non-tender. Initial resuscitation was provided in accordance with ATLS and sepsis guidelines. Anesthetic input was sought and the patient was transferred to the intensive care unit for continued resuscitation in the form of central venous pressure monitoring and inotropic support prior to emergency operative intervention. The patient's condition was deemed too unstable for transfer to the radiology department for preoperative imaging.

In theatre, initial incision of the scrotum and examination of the scrotal contents revealed necrotic loops of small and large bowel. Mesenteric thickening was noted at the neck of the hernia sac. In light of this, a midline laparotomy incision was made and the necrotic hernial contents were reduced into the abdominal cavity

TP Burke ${ }^{1}$, KM Joyce ${ }^{1}$, K Ahmed ${ }^{1}$, PS Waters ${ }^{1}$, W Khan ${ }^{1}$, K Barry ${ }^{1}$

Affiliations: ${ }^{1}$ Department of Surgery, Mayo General Hospital, Castlebar, Co. Mayo, Ireland.

Corresponding Author: Thomas Patrick Burke, 36 Grattan Park, Salthill, Galway, Ireland; Ph: 00353-851403432; Email: tpburke85@gmail.com

Received: 03 February 2014

Accepted: 08 MArch 2014

Published: 01 June 2014

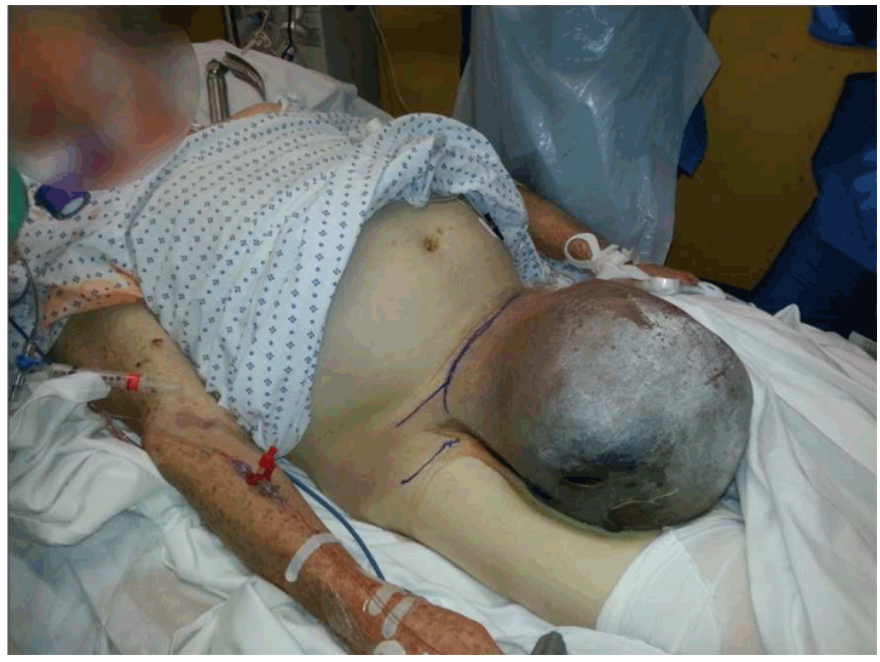

Figure 1: A clinical photograph taken preoperatively showing the giant inguinoscrotal hernia with black discolored overlying scrotal skin. The white appearance is secondary to application of topical cream by the patient prior to presentation to the emergency department.

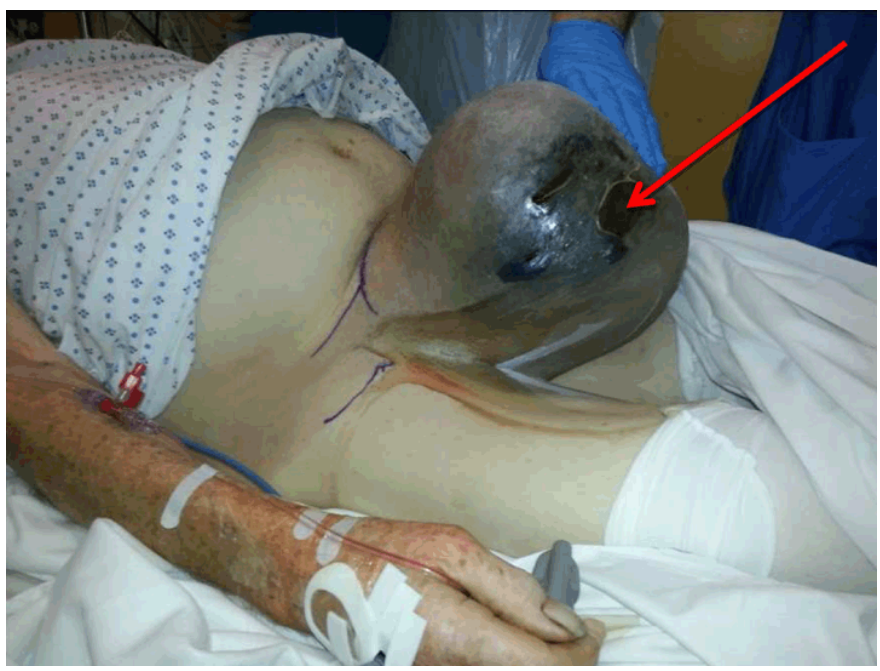

Figure 2: A clinical photograph with an arrow highlighting one of the several fluid filled bullae present on the scrotal skin. 
to determine viable resection margins. Approximately, $180 \mathrm{~cm}$ of small bowel and $20 \mathrm{~cm}$ of cecum and ascending colon were deemed non-viable and were resected leaving approximately 120 $\mathrm{cm}$ of viable jejunum. An end jejunostomy was fashioned in the left iliac fossa in order to avoid a rapidly evolving cellulitis extending from the right groin into the right iliac fossa. The fascial layer of the laparotomy incision was then closed using a standard continuous absorbable suture technique. In addition to the involved necrotic bowel, all involved scrotal tissue was aggressively debrided, this included resection of a necrotic right testicle and the majority of the scrotal skin. This wound was left open and dressed with betadine soaked swabs. During the procedure, the patient displayed significant electrocardiographic changes which included several runs of non-sustained ventricular tachycardia.

Postoperatively, hewastransferredbacktotheintensive care unit intubated. Over the initial postoperative days, his inotropic requirement declined and was discontinued on the fourth postoperative day. Extubation occurred on fifth day and sips were introduced on sixth day. He was transferred back to the ward on post postoperatively day-11. His scrotal wound was healing well by secondary intention. Delayed reversal of the end jejunostomy and definitive management of the hernial defect is planned at a later date, if necessary.

\section{DISCUSSION}

Giant inguinoscrotal hernias are defined as those that extend below the midpoint of the medial thigh in the standing position [1]. These hernias are rare in the developed world and are generally seen in clinical practice after years or even decades of self-neglect [2]. Complications of these hernias in addition to the complications common to all hernias i.e., incarceration, obstruction and strangulation also include visceroptosis, reduction in mobility, intertrigo leading to ulceration of the scrotal skin, voiding difficulties, stretching of the spermatic cord which can lead to testicular atrophy and necrosis [3]. The combination of these complications has been shown to lead to psychological sequelae and social isolation [4].

Surgical repair of giant inguinoscrotal hernia, both in the elective and emergent setting poses a number of technical challenges. A multidisciplinary approach involving anesthetists, surgeons and plastic surgeons is required to provide the best possible outcome for these patients.

These patients frequently have significant co-morbid conditions which have been sub-optimally managed due to a setting of personal neglect which can impact on both initial surgical decision making and postoperative morbidity and mortality [5]. Electively, consideration has to be given to how best to reduce hernial contents back into the abdominal cavity that have lost their "right of domain" in order to minimize the patient's risk of developing abdominal compartment syndrome. Abdominal compartment syndrome is characterized by respiratory and cardiac compromise due to splinting of the diaphragm and reducing venous return by compression of the inferior vena cava due to increased abdominal pressures. In the past, two general principles have been advocated. These include increasing the abdominal space by means of (a) progressive pneumoperitoneum, (b) abdominal wall separation or (c) combined mesh and flap techniques [6]. Tensor fascia lata musculocutaneous flaps and scrotal skin flaps are the most well described [2]. Alternatively, debulking of the hernia contents via limited resection prior to reduction into abdominal cavity has also been reported with some success [4]. In the emergent setting, principles of management include preoperative resuscitation, radical debridement of necrotic tissue, minimizing length of surgery and leaving wounds open with a view to performing staged procedures at a later date [6].

Postoperative issues following repair of giant inguinoscrotal hernias in addition to requiring intensive monitoring in the intensive care unit setting include high risk of recurrence and wound dehiscence due to increased intra-abdominal pressure. Redundant scrotal skin poses another problem. Some documented cases report good outcomes with primary resection of redundant scrotal skin however others advocate that that it acts as a safety net to allow contents back into the scrotum if respiratory compromise occurs [5]. In addition, the dartos muscle contracts and thus reducing the appearance of the redundant skin. If necessary, a planned cosmetic procedure can be performed at a later date [7].

\section{CONCLUSION}

The surgical management of giant inguinoscrotal hernias, both electively and in the emergent setting pose a unique set of challenges to the surgeon. A multidisciplinary approach combined with careful preoperative optimization and intensive postoperative monitoring is required to achieve the best possible outcome for the patient.

\section{How to cite this article}

Burke TP, Joyce K, Ahmed K, Waters PS, Khan W, Barry K. Giant inguinoscrotal hernia: An emergency presentation with life-threatening sepsis. Int J Case Rep Images 2014;5(6):456-458.

doi:10.5348/ijcri-201457-CL-10045 


\section{Author Contributions}

Thomas Patrick Burke - Substantial contributions to conception and design, Acquisition of data, Analysis and interpretation of data, Drafting the article, Revising it critically for important intellectual content, Final approval of the version to be published

Kenneth Joyce - Analysis and interpretation of data, Drafting the article, Revising it critically for important intellectual content, Final approval of the version to be published

Khalid Ahmed - Analysis and interpretation of data, Drafting the article, Revising it critically for important intellectual content, Final approval of the version to be published

PS Waters - Analysis and interpretation of data, Drafting the article, Revising it critically for important intellectual content, Final approval of the version to be published W Khan - Analysis and interpretation of data, Drafting the article, Revising it critically for important intellectual content, Final approval of the version to be published Kevin Barry - Analysis and interpretation of data, Drafting the article, Revising it critically for important intellectual content, Final approval of the version to be published

\section{Guarantor}

The corresponding author is the guarantor of submission.

\section{Conflict of Interest}

Authors declare no conflict of interest.

\section{Copyright}

(C) 2014 TP Burke et al. This article is distributed under the terms of Creative Commons Attribution License which permits unrestricted use, distribution and reproduction in any medium provided the original author(s) and original publisher are properly credited. Please see the copyright policy on the journal website for more information.

\section{REFERENCES}

1. Hodgkinson DJ, McIlrath DC. Scrotal reconstruction for giant inguinal hernias. Surg Clin North Am 1984;64(2):307-13.

2. Mehendal FV, Taams KO, Kingsnorth AN. Repair of a giant inguinoscrotal hernia. Br J Plast Surg 2000;53(6):525-9.

3. Sturniolo G, Tonante A, Gagliano E, Taranto F, Lo Schiavo MG, D'Alia C. Surgical treatment of the giant hernia. Hernia 1999;3:27-30.

4. Vasiliadis K, Knaebel HP, Djakovic N, NyarangiDix J, Schmidt J, Büchler M. Challenging surgical management of a giant inguinoscrotal hernia: Report of a case. Surg Today 2010;40(7):684-7.

5. Merrett ND, waterworth MW, Green MF. Repair of giant inguinoscrotal hernia using marlex mesh and scrotal skin flaps. Aust N Z J Surg 1994;64(5):380-3.

6. Gaedcke J, Schüler P, Brinker J, Quintel M, Ghadimi M. Emergency repair of giant inguinoscrotal hernia in a septic patient. J Gastrointest Surg 2013;17(4):8379.

7. Tahir M, Ahmed FU, Seenu V. Giant inguinoscrotal hernia: case report and management principles. Int $\mathrm{J}$ Surg 2008;6(6):495-7.
Access full text article on other devices

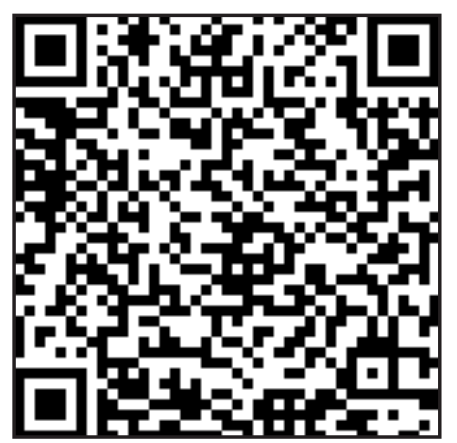

Access PDF of article on other devices

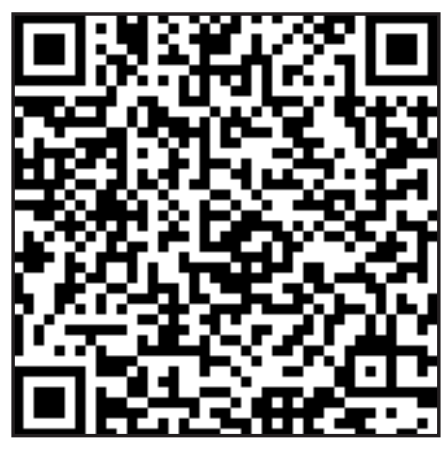

